\title{
eCOti
DiAno
}

Revista Mídia e Cotidiano

ISSN: 2178-602X

Artigo Seção Livre

Volume 15, Número 1, jan./abr. de 2021

Submetido em: 19/06/2020

Aprovado em: 08/12/2020

\section{O que adolescentes pensam sobre o compartillhamento de si na internet?}

What do adolescents think about self-sharing on the internet?

¿Qué piensan los adolescentes acerca de compartirse en Internet?

\author{
Lara Lima SATLER ${ }^{1}$ \\ Ana Júlia de Freitas CARRIJO²
}

\section{Resumo}

Analisamos neste texto os processos de atribuição de sentido feitos por adolescentes goianos à prática do compartilhamento de si na internet, especialmente na plataforma Instagram. O objetivo é mapear as percepções dos jovens sobre o compartilhar-se, a partir de um tensionamento com as práticas cotidianas de acesso que eles mesmos realizam, à luz de discussões teóricas caras aos Estudos Culturais. Para tanto, utilizamos o método cartográfico com aproximações etnográficas e realizamos entrevistas individuais em profundidade e grupos de discussão. Os resultados dissertam sobre uma postura crítica dos participantes em relação a esse uso e conduzem a análises sobre as percepções de si e do outro, em meio a um contexto de construção subjetiva efervescente na adolescência, mediado pela internet.

Palavras-chave: Compartilhamento de si. Adolescentes. Instagram.

\section{Abstract}

We analyze in this text the processes of attribution of meaning made by adolescents from Goiás to the practice of self-sharing, especially on Instagram. The objective is to map the perceptions of these young people about self-sharing, within a tension with the daily access practices that they perform by themselves, in the light of theoretical discussions of Cultural Studies. For this, we use the cartographic method with ethnographic approaches and conduct individual in-depth interviews and discussion groups. The results points a critical posture of the participants in relation to this use and lead to analyzis about the

\footnotetext{
${ }^{1}$ Bolsista de Produtividade em Pesquisa (PQ-2), CNPq. Professora nos Programas de Pós-graduação em Comunicação e Performances Culturais (PPGCom/PPGPC), Universidade Federal de Goiás (UFG). Email: lara_lima_satler@ufg.br ORCID: 0000-0002-2509-6278.

2 Mestranda em Comunicação pelo Programa de Pós-Graduação em Comunicação (PPGCom) da Universidade Federal de Goiás (UFG). Bolsista CAPES. E-mail: anajucarrijo@gmail.com. ORCID: 0000-0001-8372-1003.
} 
perceptions of themselves and of the other, in a context of subjective construction in adolescence, mediated by the internet.

Keywords: Self-sharing. Adolescents. Instagram.

\section{Resumen}

Analizamos en este texto los procesos de atribución de significado que realizan los adolescentes de Goiás a la práctica de compartirse en internet, especialmente en la plataforma Instagram. El objetivo es mapear las percepciones de los jóvenes sobre el compartir, desde una tensión con las prácticas de acceso cotidiano que ellos mismos realizan, a la luz de discusiones teóricas cercanas a los Estudios Culturales. Así, utilizamos el método cartográfico con enfoques etnográficos y realizamos entrevistas individuales en profundidad y grupos de discusión. Los resultados hablan de una postura crítica de los participantes con relación a este uso y conducen a análisis sobre las percepciones de sí mismos y del otro, en el contexto de una construcción subjetiva efervescente en la adolescencia, mediada por internet.

Palabras clave: Autocompartir. Adolescentes. Instagram.

\section{Introdução}

O hábito de uso das redes de comunicação na internet nos constitui enquanto sujeitos produtores da cultura contemporânea, já que é também por meio dele que construímos coletivamente referências e símbolos, estabelecemos acordos e valores e consolidamos parâmetros de modos de ser socialmente. Esse é um pressuposto teórico assumido em diálogo com pesquisadoras(es) vinculadas(os) aos Estudos Culturais, especialmente na América Latina, a partir da virada etnográfica e de trabalhos como de Jesús Martín-Barbero (1997). A partir dele, temos desenvolvido uma pesquisa mais ampla, que origina este texto, interessada em entender como os usos que adolescentes fazem da internet podem revelar pistas sobre a sociedade em que vivemos no presente.

Dessa maneira, apresentamos neste artigo um recorte de uma pesquisa qualitativa em Comunicação, a qual se propõe a realizar aproximações metodológicas etnográficas. Uma aproximação etnográfica na Comunicação se faz adequada quando o contato com o outro é indispensável. Porém, especialmente, quando se pretende que esse contato seja mais que um encontro para coletar informações. O método, próprio da Antropologia, que tem sido utilizado na Comunicação, desde estímulos mais evidentes dos Estudos Culturais Britânicos e Latino-Americanos (SILVEIRA, 2016), consiste na 


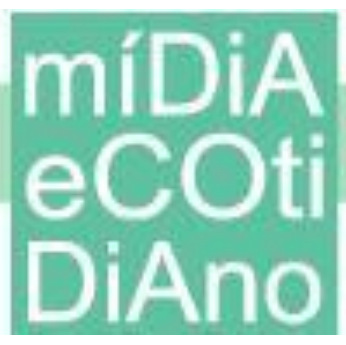

realização de uma pesquisa de campo mais prolongada, no intuito que as(os) pesquisadoras(es) possam conhecer melhor os entrevistados, fazer parte do cotidiano desses sujeitos, prezando por uma análise holística da cultura, cujo olhar está voltado às interações significativas da experiência (MATTOS, 2011). Nesse sentido, a pesquisa empírica ganha o potencial de produzir dados com os entrevistados, a partir de uma percepção mais sensível e completa da realidade vivida.

Como sustenta o campo das humanidades digitais (MACHADO, 2017, n.p.), “o digital, embora possa ser reduzido ao código binário, será também um espaço de produção de muitas diferenças e pluralidades", de modo que experiências etnográficas comparadas em diversas regiões do mundo comprovaram mudanças nas percepções e nos usos em diferentes culturas. Por isso, estamos interessadas em considerar os aspectos e usos diversos que surgiram no campo como pistas importantes da construção dos cenários comunicativos atuais.

Sob essa perspectiva, neste artigo, o intuito é analisar em que termos usuários se apropriam, resistem e produzem sentido nos processos comunicativos digitais para buscar pistas sobre as dimensões culturais e sociais de nosso tempo. Para tanto, a Teoria das Mediações, materializada na perspectiva cartográfica (MARTÍN-BARBERO, 1997; 2004), nos conduz para centrar o estudo na perspectiva dos usos sociais, que são um “conjunto de entornos que interage na construção dos significados atribuídos aos meios de comunicação e no modo como sujeito e tecnologia se relacionam" (BRIGNOL, 2010, p. 54). Trata-se dos modos pelos quais as pessoas se apropriam dos meios e da tecnologia e criam modos específicos de incorporá-los ao dia a dia. Por vezes inventivas, essas artes do fazer cotidiano (CERTEAU, 1994) afastam a noção de passividade do sujeito consumidor de conteúdos e associam a ele destrezas para relacionar-se com os meios.

Na lógica da cultura de participação (JENKINS, 2009), quanto mais usuários compartilhando conteúdos, mais atrativos tornam-se os ambientes de navegação. Um dos usos da internet que tem se destacado nesses espaços, especialmente na plataforma Instagram, é o compartilhamento de si mesmo. Nessa prática, em que o sujeito que fala é também o sujeito de quem se fala, os usuários da rede registram momentos do cotidiano, no formato de fotos ou vídeos curtos, e compartilham-nos em uma página pessoal chamada de perfil. 
Interessa-nos analisar aqui as percepções de jovens usuários da internet acerca do uso voltado ao compartilhar-se. Buscamos nos aproximar etnograficamente de um grupo de 12 adolescentes entre 15 a $17 \operatorname{anos}^{3}$ para ouvi-los e conhecer os caminhos envolvidos no processo de atribuição de sentido às práticas comunicativas em que sujeitos comuns tornam-se potenciais conteúdos na internet. Os participantes da pesquisa foram estudantes de um colégio estadual de ensino médio localizado no município de Aparecida de Goiânia, Goiás, e o trabalho foi feito seguindo todas as orientações éticas necessárias. Dos 12 participantes, 7 se identificam com o gênero feminino e 5 com o masculino. Todos moram com familiares, 10 são solteiros e 2 disseram estar namorando. Quanto à raça e cor, 8 se declararam brancos, 2 pretos, 1 pardo e 1 amarela (asiática). Sobre a renda familiar, 9 indicaram ser de 1 a 3 salários mínimos, 2 de 3 a 6 salários mínimos, 1 de 6 a 9 salários mínimos.

A seguir, apresentamos um recorte da análise dos dados produzidos em campo com esses jovens, cujo objetivo é mapear os modos de uso manifestados pelo grupo, problematizando as impressões sobre as dinâmicas contemporâneas do compartilhar-se, a partir de um tensionamento com as práticas efetivas de acesso que eles mesmos realizam. Isso, à luz de discussões teóricas caras aos Estudos Culturais, capazes de promover análises sobre as percepções de si e do outro e ainda sobre os processos de construção subjetiva efervescentes na adolescência, em uma perspectiva relacional/social mediada pelo uso da internet.

Registramos que, em busca de uma escrita etnográfica polifônica, inserimos transcrições das falas dos participantes de forma direta no texto, sempre que possível, e optamos por não numerar os colaboradores, nem criar nomes fictícios, nem revelar seus nomes reais. Desse modo, nossa voz e as vozes dos colaboradores integram-se e constroem, em conjunto, um único texto, tornando a polifonia mais evidente. Apesar disso, utilizamos as aspas para demarcar o início e o fim das aparições dessas outras vozes.

\footnotetext{
${ }^{3}$ Embora no Brasil, o Ministério da Saúde marque a adolescência com a delimitação etária de 10 a 19 anos e a juventude de 15 a 24 anos (HORTA e SENA, 2010), estamos cientes dos debates acerca da noção de "adolescência", vinculada ao panorama estadunidense dos "teenagers" (COIMBRA et al, 2005). Em nosso trabalho, utilizamos os termos adolescência/adolescentes e juventude/jovens, como sinônimos, para nos referirmos aos colaboradores da pesquisa.
} 


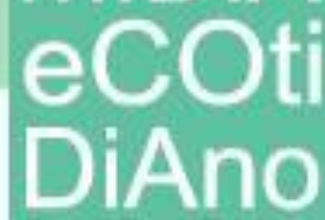

\section{Compartilhar-se?}

Na dinâmica empírica, principalmente nos primeiros contatos com o grupo, a maioria dos participantes não quiseram falar com profundidade sobre o tema, como se houvesse certo desprezo com relação ao uso da internet para compartilhar-se. $\mathrm{O}$ tom crítico revelou um desejo dos adolescentes em apresentar, nos encontros iniciais, uma maturidade de pessoas que não se interessam por "esse tipo de coisa", como afirmou um deles. Isso é um dado interessante porque revela os adolescentes resistindo a um uso comum da internet, o que vai na contramão de uma ideia geral sobre a atuação dos jovens nas redes sociais - ideia essa que, inclusive, embasou a elaboração do projeto inicial da pesquisa que origina este artigo.

Tanto o discurso institucional dessas plataformas indica o compartilhar-se como uso principal, quanto o grande número de pessoas envolvidas em redes organizadas em torno da publicação de conteúdos pessoais, justificam nosso interesse por essa perspectiva. Nesse sentido, a pesquisa empírica é uma abordagem potente quando o interesse é desviar o percurso cartográfico de uma crítica essencialista do fenômeno tecnológico, a qual instrumentaliza os dispositivos e produz visões generalizantes, desconsiderando os rastros deixados por quem constrói os fatos comunicativos observados (LEMOS, 2015). No âmbito da apropriação e do uso, tais rastros são centrais para a análise.

A noção de apropriação, tal como discutida por Martín-Barbero (1997) e Orozco Gómez (2005), é importante nesse sentido, já que trata dos modos pelos quais os usos das mídias são valorados no processo social, indicando os trilhos sobre os quais os sentidos possíveis serão gerados e ainda (des)considerados, respeitados, criticados. Apropriar-se desse tipo de conteúdo midiático significa não só interpretá-lo, mas tensioná-lo com a rede de comunicação cotidiana de cada sujeito, inquiri-lo a partir dos discursos institucionais que permeiam o universo particular de cada um, inseri-lo no escopo de repertório e ajustá-lo às referências disponíveis. Trata-se de um processo orientado na esfera das competências de recepção, na qual são desenvolvidas as destrezas necessárias para a materialização das dinâmicas de apropriação.

A resistência inicial dos colaboradores ao compartilhar-se é um modo e um exemplo de apropriação desse uso que ocorreu no campo. A postura crítica e o tom 


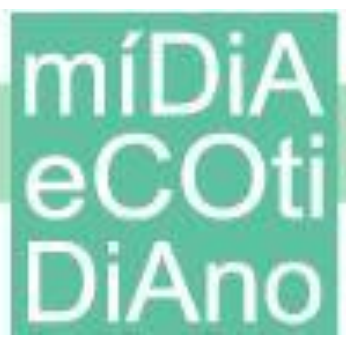

pejorativo dos adolescentes instigou ainda mais nosso labor cartográfico. Quais as razões para que eles tenham se posicionado assim? Compreendemos que essa postura está associada a um amplo discurso cultural que desvaloriza as produções da internet, classificando-as como menores, desimportantes, como um amadorismo chulo. Esse posicionamento pode ser mediado por diversas "comunidades de apropriação" (GÓMEZ, 2005), tais como as instituições família e escola, que podem se mostrar resistentes aos conteúdos produzidos ali e também alguns setores da mídia tradicional, que enfrentam o boom de redes sociais e "influenciadores digitais", denunciando ou menosprezando suas atividades.

Não podemos ignorar também a mediação institucional (MARTÍN-BARBERO, 2004) da escola em que estivemos na pesquisa. Sendo o ambiente de realização dos encontros, toda a estrutura de poder envolvida na dinâmica dos estudantes (coordenação, direção, obrigações, notas) permeou nossos encontros. Prova disso foi o hábito dos estudantes de nos chamar de "professora", mesmo que tenhamos esclarecido que nossa função ali não era de docente. Além disso, compartilhamos desde o início nosso vínculo com a Universidade, ressaltando que aquela experiência tratava-se de uma pesquisa científica da pós-graduação, devidamente produzida segundo as normas da instituição e do comitê de ética. Como muitos disseram abertamente, essa foi a primeira experiência deles com o universo acadêmico. Logo, o peso social que eles atribuíram ao processo também mediou as respostas e os discursos sustentados sobre eles mesmos.

Considerando tais questões e respeitando a visada crítica lançada pelos adolescentes, buscamos ouvir com atenção o que eles tinham para dizer sobre o compartilhar-se, para além da crítica inicial. Ao longo dos encontros, percebemos que o tom pejorativo não era o único modo de apropriação do compartilhar-se. Descobrir outras camadas com o grupo só foi possível por conta da escolha metodológica de realizar mais de um encontro com os jovens (estivemos com eles por três meses). Nessas oportunidades, realizamos tanto entrevistas individuais (DUARTE, 2010), quanto discussões em grupo (GASKELL, 2002), acessamos juntos materiais disponibilizados no Instagram em perfis que eles costumam acompanhar, conversamos sobre eles, sobre as interações deixadas nas páginas, enfim, criamos possibilidades de diálogo que pudessem aprofundar o debate sobre o uso social em questão. Portanto, os dados que apresentamos 


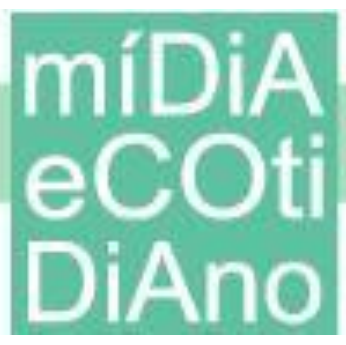

aqui foram produzidos em momentos diferentes, em conversas livres, outras em formato de entrevista, tanto repetindo as mesmas perguntas a todos, quanto ajustando o roteiro de acordo com o entrevistado.

Essa articulação de técnicas expande as potencialidades do trabalho e traz complexidade à análise, como é próprio da perspectiva etnográfica que assumimos. Neste texto, há um compilado de vários momentos vividos em campo, cuja discussão em forma de artigo é um esforço intelectual, inspirado na densidade recomendada por Geertz (1989), de descrever, analisar, tensionar pontos de vista, articular sensibilidades e percepções. Trata-se de uma tentativa de organização da realidade acessada, certamente menos complexa que ela, que pretende apresentar ao leitor e à leitora as percepções cartografadas com os adolescentes. Daí a necessidade de agrupar respostas e opiniões em eixos desenhados na análise, mesmo que elas tenham aparecido de forma mais fluida no campo.

\section{As performances do compartilhar-se}

Buscamos entender quais são, na opinião dos entrevistados, as razões que levam as pessoas a compartilharem conteúdos relacionados ao dia a dia na internet. Obtivemos diversas possibilidades argumentativas para sustentar esse uso. Na maioria dos casos, a resposta de uma pessoa apresentou pelo menos duas razões distintas, o que nos fez perceber que eles enxergam o compartilhar-se como uma atividade ampla, praticada de diferentes modos e com objetivos múltiplos - propriamente cultural. Contudo, todas as motivações citadas tiveram um ponto central em comum: a relação com o outro. Agrupamos as opiniões em cinco blocos também a partir dos dados produzidos com os jovens, que vão desde uma valoração positiva até uma crítica mordaz.

O primeiro motivo para as práticas de compartilhamento de si na internet apresentado por eles foi o compartilhar-se como forma de enfrentar a solidão. Segundo eles, pessoas que são mais sozinhas tendem a fazer mais postagens sobre elas mesmas. $\mathrm{O}$ uso da internet torna-se, então, um caminho de busca por atenção e diálogos on-line. Os adolescentes disseram ser muito comum o hábito de pessoas mais carentes preferirem se expressar pela internet que nas "interações face a face", nos termos de Thompson (2018). Também nas reflexões sobre a sociedade em rede, Castells (1999) já indicava que a 


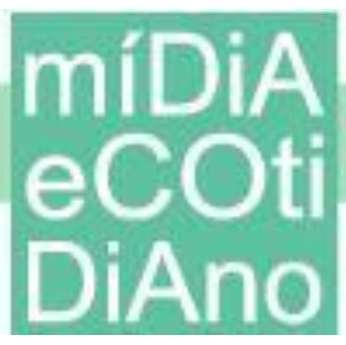

internet estaria trazendo "algum alívio a pessoas carentes de comunicação e autoexpressão" (CASTELLS, 1999, p. 443). Quem disse isso, entre nossos colaboradores, não pareceu se incomodar com esse uso. Ao contrário, destacou que essa possibilidade de se expressar pelas redes sociais pode auxiliar muita gente que precisa de apoio psicológico.

Uma segunda opinião sobre o que leva as pessoas a falarem sobre sua vida na internet é o desejo de dividir encantos e sucessos com outras pessoas. Trata-se de um desejo de criar um vínculo positivo com os seguidores, compartilhando coisas boas que acontecem na própria vida. Segundo os entrevistados, "as pessoas sentem que as outras pessoas ficam felizes com o sucesso, os avanços delas" e que, "às vezes, acontece um negócio fora do normal e eu fico 'nossa eu preciso mostrar isso aqui'". Nessa esfera, foi destacado que deve haver "bom senso" na hora de decidir o que postar, para que somente "aquilo que vale a pena" seja compartilhado. Contudo, essa definição foi imprecisa, já que, como disseram, depende de uma análise específica para cada situação prática.

Uma terceira linha argumentativa apareceu quando uma das entrevistadas mencionou a motivação financeira para justificar desejo de compartilhar-se. A prática daqueles que ela chamou de "anônimos famosos" de sempre postar sobre si para "manter o status" é também um "modo de ganhar dinheiro" porque as lógicas de produção dos produtores de conteúdo on-line têm se articulado aos circuitos publicitários como uma mídia importante. As empresas se valem da proximidade construída pelo(a) produtor(a) com os seguidores e inserem seu discurso institucional de produtos e serviços na esfera de credibilidade produzida pela atuação no cenário digital.

O quarto grupo de opiniões defendeu que compartilhar-se é um hábito de lazer: "é algo rotineiro, que você faz com um amigo conversando, é muito gostoso de fazer". Essa motivação destaca o caráter despretensioso e espontâneo que essa prática pode ter e ressalta sua perspectiva relacional, o que vai ao encontro do uso mais recorrente das primeiras formas de serviços de telecomunicação com videotextos, como o Minitel, na França, em 1984, que fez sucesso especialmente a partir da apropriação do povo francês para práticas de expressão pessoal em linhas de mensagem e bate-papo (CASTELLS, 1999).

Os participantes que desenvolveram essa linha argumentativa afirmaram que esse tipo de interação acontece principalmente nos stories do Instagram e nos status do 
WhatsApp (recurso oferecido por essa outra plataforma que se assemelha muito àquele desenvolvido pelo Instagram). Segundo eles, nesses formatos, as produções são mais espontâneas e geram a sensação de "uma pessoa contando alguma coisa para os amigos". Isso se deve ao número menor de edições (em comparação com o YouTube), à duração limitada de tempo para visualização (24 horas) e ao hábito de instantaneidade desenvolvido pelos usuários, ou seja, o costume de postar exatamente no momento do acontecimento, pois assim "você fala o que vem na sua cabeça".

Pensando a partir da tecnicidade (MARTÍN-BARBERO, 2004), a opinião dos entrevistados indicou que os operadores de percepção envolvidos nesse uso revelam uma intenção de transparência dos produtores, os quais se valem da mediação tecnológica do formato e dos usos sociais consolidados para sustentar a espontaneidade das postagens e criar uma sensação de proximidade com quem assiste. Essa destreza de linguagem desenvolvida junto com os arranjos técnicos parece estar cada vez mais produzindo possibilidades de viabilizar o compartilhar-se enquanto diversão de uma conversa entre amigos. Prova disso é o recurso "melhores amigos" ("close friends", em inglês), criado pelo Instagram em novembro de 2018, que permite ao produtor selecionar uma lista de amigos dentre todos os seguidores de seu perfil para os quais deseja disponibilizar seus stories. É o que Suely Fragoso (2012, p. 70) entende como a "possibilidade de compartilhamento em várias escalas", segundo a qual é possível indicar quem deve e quem não deve ter acesso a determinados conteúdos. Quando um usuário visualiza o story ${ }^{4}$ de alguém que o inclui nessa lista restrita, a cor da notificação muda e o canto direito superior da tela indica que ele é um dos melhores amigos daquela pessoa. Nesse caso, os stories costumam ser ainda mais espontâneos, como apontaram os entrevistados.

Essa consideração começa a revelar uma pista importante sobre a prática de compartilhar-se, que é o conjunto de ajustes performáticos utilizados em diferentes situações comunicativas. No exemplo dos melhores amigos, a postagem fica "mais ou menos espontânea", para usar os termos dos entrevistados, de acordo com as pessoas que

\footnotetext{
4 Instagram Stories é um recurso disponibilizado em 2016 na plataforma Instagram. Trata-se de uma ferramenta que possibilita a publicação de fotos e vídeos efêmeros, que desaparecem após 24 horas. Cada publicação, chamada de story, aparece na tela por um tempo máximo de 15 segundos e pode ser revista sem limites até o prazo das 24 horas.
} 
poderão acessá-la. Isso revela um processo de construção de diferentes versões de si a serem compartilhadas, fenômeno que pode ser elucidado pela teoria de Erving Goffman (2018), especialmente quando o autor discute sobre sobre $A$ representação do eu na vida cotidiana. A grande contribuição do sociólogo é indicar que cada ator social constrói diferentes representações de si mesmo, que variam de acordo com as ocasiões e com o público. Essas representações são construídas para que o agente tente controlar as impressões deixadas no outro e consiga construir e "manter narrativas biográficas coerentes" (GIDDENS, 2002, p. 13). Essa habilidade é uma competência social desenvolvida a partir da interação e faz parte de um movimento cultural, cujas matrizes valorizam a destreza de saber portar-se adequadamente em cada situação.

Em um nível analítico mais profundo, representar a si está relacionado ao processo de construção subjetiva, afinal, para contar-se é preciso fazer-se, descobrir-se. É o que discute Silverstone (2002) ao frisar que

a modernidade trouxe consigo [...] a intensificação [de] comportamentos performativos, os quais criam tanto o social como o individual e permitem ao performer não só apresentar-se para o outro, mas revelar-se a si mesmo - um ato essencialmente reflexivo (SILVERSTONE, 2002, p. 132-133).

Nesse sentido, Giddens (2002) entende tal movimento como um projeto reflexivo do eu, isto é, um exercício contínuo de pensar a vida pessoal como um processo de construção de autoimagem(ns), feita(s) e refeita(s) a partir de decisões cotidianas.

A necessidade de construir uma autoimagem, ou mais, para relacionar-se com os outros confere ao sujeito contemporâneo múltiplas possibilidades e exige ajustes performáticos específicos para controlar as impressões deixadas. Quando Goffman (2018) discute sobre a representação de si na vida cotidiana pressupõe-se que, para representar a si mesmo, é preciso escolher, dentre as identidades possíveis, aquelas ajustadas aos objetivos de quem representa, isto é, escolher estilos de vida congruentes com a(s) narrativa(s) particular(es) que constrói(em) e é (são) construída(s) pelo sujeito (GIDDENS, 2002). O plural destaca que essas narrativas de si podem ser várias, desenvolvidas em uma “celebração móvel” (HALL, 1997, p. 13) de identidades fluidas e 


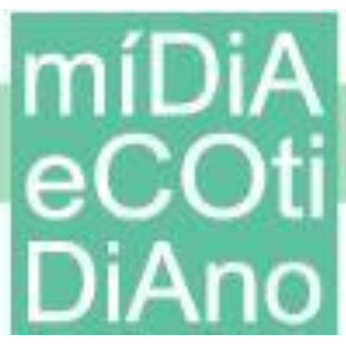

cambiantes. Desse modo, a construção subjetiva passa a ser um processo constante de elaboração de si mesmo(a) diante de uma infinidade de possíveis modos de ser.

A internet, de forma ampla, configura-se como um dos espaços sociais que ambientam A aventura de contar-se (RAGO, 2013). Dentro dela existem várias situações específicas que demandam ajustes na performance de quem participa do circuito de interações. Diversos regimes de tecnicidade medeiam o processo de aprendizado envolvido em saber escolher a plataforma, o recurso e o momento adequado para postar cada tipo de conteúdo. E mais: os operadores de percepção devem ser aguçados para construir com coerência os modos de aparição para os outros. Esse processo de controle sobre as representações transmitidas foi exemplificado por uma das entrevistadas, quando, com muita facilidade, disse que cada plataforma "serve" para momentos específicos: "Facebook é pra postar foto de família, Instagram é mais pra compartilhar o momento e YouTube é pra vídeo com mais qualidade".

Mônica Machado (2017), afirma que

o que motiva, por exemplo, um jovem a escolher o Facebook como plataforma e não o Instagram ou o Snapchat [...] é um conjunto de variáveis: acesso à infraestrutura, custo, experiências de literacia, empatia, vínculos emocionais, regras de sociabilidade (MACHADO, 2017, n.p.).

A percepção dessas variáveis, em especial das regras de sociabilidade, decorre do uso e da observação do que é socialmente construído em cada cenário da web. Destacamos que não só o conteúdo parece ser específico, como também as características das representações em cada plataforma.

O fenômeno é tão complexo que em uma mesma plataforma (o Instagram), dentro de um mesmo recurso (os stories), os entrevistados indicaram diferentes tipos de representação, organizadas por eles em graus de espontaneidade. No exemplo citado, os stories para os melhores amigos são feitos com representações mais espontâneas de si, porque o público é menor e selecionado de acordo com a proximidade com o(a) produtor(a). Já os stories para todos os seguidores são, seguindo a mesma lógica, menos espontâneos. Nessa gradação, o grupo revelou que as postagens do feed no Instagram são menos espontâneas ainda porque, diferentemente dos stories, que só duram 24 horas, elas 


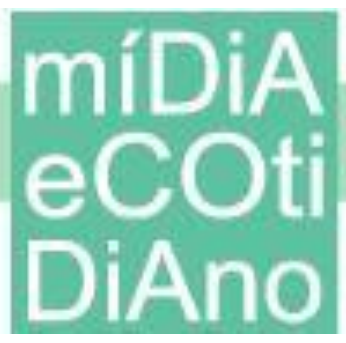

ficam disponíveis para todos os seguidores por tempo indeterminado, até que o(a) administrador(a) as exclua. Desse modo, de acordo com os dados produzidos em campo, quanto maior a proximidade entre produtor e público e quanto menor a duração da disponibilidade da postagem, maior será a espontaneidade da representação de si.

Para seguirmos nesse eixo de discussão, trazemos a quinta justificativa apontada para as motivações de compartilhar-se na internet: a busca por exibir-se. Esse bloco de opiniões é um pouco mais complexo porque apresentou diferentes níveis de crítica à autoexibição, todos eles com um tom pejorativo. Os menos incisivos disseram que essa prática "é só para mostrar mesmo", que tem "o objetivo de mostrar para os outros" e "querer alguma coisa com isso". Nessa linha, a crítica foi ficando mais explícita: é "para poder se achar" porque "a pessoa acha que a vida dela é tão incrível que as outras pessoas também têm que ver". Até chegar nas falas mais categóricas: "é para mostrar... para passar uma imagem de algo que você não é para alguém”, “isso é querer provar para os outros, mas no fundo querer provar para ela mesma, que ela tem uma vida aceitável, uma vida feliz, uma vida em que o tempo inteiro você é realizada e tá tudo bem o tempo inteiro".

Tais falas reiteram a discussão sobre performance nas redes sociais, que, há um tempo, tem sido objeto de nossas discussões (CARRIJO; SATLER, 2019). A performance é uma prática de representação de si que pode ser entendida, de acordo com Schechner (2002), como a ação de ser, fazer, mostrar sendo ou mostrar fazendo. Cada ação demanda diferentes ajustes performáticos vinculados ao objetivo de quem performa. A ação de fazer alguma coisa demanda que o agente se preocupe com as normas sociais de comportamento necessárias para que ele possa realizar a ação. Já a ação de mostrar fazendo alguma coisa demanda, além disso, os ajustes para que a impressão que o agente deseja ser refletida em sua performance chegue aos observadores. Esse processo de mostrar-se sendo ou fazendo é materializado no uso da internet que estamos estudando: utilizar a câmera do próprio celular para registrar e compartilhar as atividades do dia a dia. Concluímos que as performances do compartilhar-se são exercícios de representação de si para mostrar-se sendo ou fazendo algo, com vistas à apreciação de outras pessoas.

Goffman (2018) define representação como "toda atividade de um indivíduo que se passa num período caracterizado por sua presença contínua diante de um grupo particular de observadores e que tem sobre estes alguma influência" (GOFFMAN, 2018, 
p. 34), logo toda representação tem como referência o olhar do outro. A importância desse valor relacional varia de acordo com o controle que o ator social deseja ter em relação às impressões geradas: quanto mais controle for desejado, maior deverá ser a atenção à perspectiva de quem assiste. Nesse sentido, as performances mais espontâneas (ser/fazer) estabelecem uma relação menos intensa com o julgamento do outro, por isso são mais despretensiosas, como os adolescentes apontaram. Já aquelas que visam à visibilidade, estão intrinsecamente relacionadas à apreciação do outro. Portanto, são construídas com maior cuidado para que alcancem o objetivo pretendido: expressar a si mesmo de acordo com o modo pelo qual quer ser percebido socialmente.

Enquanto a primeira opinião do grupo discutida anteriormente (compartilhar-se para dialogar com amigos) visa à performance do ser/fazer, esse segundo bloco de opiniões critica a performance do mostrar-se sendo/mostrar-se fazendo. Este modo de representação do eu gera um incômodo nos entrevistados, o qual pode ser explicado como um descompasso entre "o que mostra e o que é de verdade", nos termos dos entrevistados, ou entre a fachada e a região de fundo, nos termos de Goffman (2018).

Fachada [é] a parte do desempenho do indivíduo [...] com o fim de definir a situação para os que observam a representação. [...] É o equipamento expressivo de tipo padronizado intencional ou inconscientemente empregado pelo indivíduo durante sua representação (GOFFMAN, 2018, p. 34, grifo nosso).

A partir de Goffman (2018), Thompson (1998), também reflete sobre os processos de interação e mediação articulados à fachada.

Ações e expressões pessoais que se sentem inapropriadas, ou que poderiam desacreditar a imagem que a pessoa está procurando projetar, são suprimidas e reservadas para outros ambientes e encontros - para ambientes que podem ser descritos com 'regiões de fundo' com relação à fachada em que a ação acontece (THOMPSON, 1998, p. 82).

\footnotetext{
${ }^{5}$ Destacamos que não é intrínseca à discussão aqui construída qualquer indicação de valores positivo ou negativo ao ato de performar, ou de representar a si mesmo nas fachadas. Trata-se apenas de uma reflexão teórica sobre as práticas de comunicação próprias de nossa cultura.
} 
A partir desses conceitos, registramos que a sensação de que algumas pessoas usam a internet para se exibirem, construindo uma imagem delas mesmas que não coaduna com a realidade representa a expressão de uma fachada significativamente diferente da região de fundo. Decorre disso que o uso social das plataformas de comunicação voltado para o compartilhamento de si pode desenhá-las como um espaço social de visibilidade, em que se deve manter uma performance de afirmação de si enquanto sujeito admirável. É o que aparece na discussão travada com um dos participantes reproduzida integralmente a seguir:

Pesquisadora: Você já sentiu vontade de postar algo sobre você na internet?

Entrevistado: Já, já! Quando você começa a fazer academia não tem outra história, né? A gente tem que mostrar que eu não sou sedentário, eu faço alguma coisa da minha vida! Eu sei pendurar na argolinha, eu sei girar! É muito legal!

Pesquisadora: E quando você está treinando, você filma você fazendo os exercícios?

Entrevistado: Não, não... Eu tenho muita vergonha! Eu acho o povo tirando foto na rua muito ridículo... Falo: "gente não vou passar essa vergonha". Aí eu não vou chegar no meio da academia, todo mundo fazendo exercício, eu pegando celularzinho pra fazer os negócios.

Pesquisadora: E o que você posta pra falar que você tá na academia?

Entrevistado: Ah, sei lá, tem vez que tem tipo um... porque o próprio povo da academia filma né, tipo pra divulgar o Instagram deles... os exercícios e tal. Aí às vezes eu apareço, aí eu publico no meu.

Pesquisadora: Mas você mesmo não registra?

Entrevistado: Não, tem uns que eu consigo fazer em casa, aí eu gravo alguns, mas é bem raro.

Pesquisadora: Foto no espelho?

Entrevistado: Não, eu tenho vergonha... Todo suado, que nojo!

Pesquisadora: Mas por que vergonha? Você quer que as pessoas te vejam no Instagram, mas você não quer que as pessoas te vejam fazendo a foto?

Entrevistado: É! É um tipo de... bom, quero mas não eu, entendeu? Um eu só que não eu mesmo, sabe? É difícil de entender. É tipo um rato borrachudo... ele nunca mostrou o rosto, ele só usa a mascarazinha de rato.

Pesquisadora: É como se no Instagram você não fosse você você mesmo?

Entrevistado: Não... é que eu não queria ser eu, mas infelizmente eu sou. Ah, é difícil de entender... Às vezes, você se acha não tão interessante mas você quer publicar alguma coisa interessante. Só que eu, em mim mesmo, não sou tão interessante, mas se eu fizesse alguma coisa de interessante eu queria que não fosse eu. Dá pra entender? Eu 
queria me admirar que nem as outras pessoas me admirariam. Queria que o que eu postasse fosse algo que eu gosto, mas que eu também sou. É uma parte de mim, mas eu não quero ser eu porque eu tenho vergonha.

Esse diálogo revela a complexidade do processo de postar sobre si mesmo, especialmente relacionado à visão dos outros. Quando esse adolescente compartilha conosco as preocupações com a imagem que deseja transmitir, ele denota, dentre outras coisas, uma tendência de "oferecer a seus observadores uma impressão que é idealizada", inclusive por ele, incorporando "valores oficialmente reconhecidos pela sociedade" (GOFFMAN, 2018, p. 47-48), os quais fazem parte de suas referências individuais sobre como se deve ser (ou ser visto). O trecho transcrito anteriormente revela um desejo do adolescente de ser alguém admirável para que suas postagens pudessem revelar aos outros esse lado a ser admirado. Destacamos o conflito do jovem ao dizer que não se acha tão interessante, mas que gostaria de sê-lo para que suas postagens fossem autênticas, ou seja, falassem do que ele é de fato (um sujeito admirável): "queria que o que eu postasse fosse algo que eu gosto, mas que eu também sou".

Isso nos parece uma busca por construir uma narrativa coerente sobre si em relação ao que se é de verdade, presumindo a existência de uma entidade essencial no interior de cada um, que sustenta o que estamos chamando aqui de autenticidade. E mais: presumindo também que essa verdade devesse ser boa o suficiente, isto é, enquadrada no padrão social idealizado, para ser compartilhada. Essa perspectiva intimamente vinculada à noção moderna de sujeito (SANTAELLA, 2004) aparece também em outras falas já discutidas anteriormente, como aquelas que afirmam o compartilhar-se como a exibição de si "para passar uma imagem de algo que você não é". Essa crítica também parece presumir uma autenticidade que existe, mas não está sendo mostrada - está sendo substituída por uma outra representação de si.

Nesse ponto, precisamos pensar a partir de duas potências do fenômeno analisado: (a) o compartilhar-se é um ato performático de construção de narrativas sobre si; (b) existe uma demanda por autenticidade nas postagens sobre si. Para Sibilia (2015), estaríamos diante de um paradoxo, vivendo ao mesmo tempo a era da performance e a era da autenticidade. Tratar-se-ia de um paradoxo porque "a crença na autenticidade do eu pressupõe uma peculiar relação com a verdade [...] enquanto a performance parece 


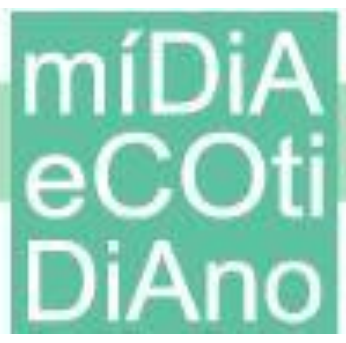

enfatizar o artifício e a encenação" (SIBILIA, 2015, p. 358). Compreendemos os desdobramentos dessa afirmação, que conduzem para o estabelecimento de diferentes lugares de edificação da subjetividade, cada vez mais voltados para o exterior do ser que para o seu interior (RIESMAN, 1995). Contudo, nos parece frágil a associação direta da performance a algo pejorativo e vinculado ao oposto da verdade.

\section{Considerações}

No intuito de conhecer de perto os usos sociais que adolescentes fazem da internet, pudemos nos aproximar do universo dos jovens entrevistados e perceber caminhos particulares e coletivos de mediação. Eles vieram à tona nos mecanismos de atribuição de sentido a práticas comunicativas cotidianas, especialmente aquelas relacionadas ao compartilhar-se, que é o recorte apresentado aqui. Assim, as entrevistas e todas as discussões que compõem a etnografia fazem parte de um movimento mais amplo de elaboração de opinião, o qual é mediado por diversas instituições (a família aparece com mais força em algumas falas, a escola em outras, a igreja em outras), mas primordialmente sustentado pelo uso das redes sociais digitais, isto é, pela observação dos outros usuários em ação e pela análise da própria atuação enquanto produtores. Por isso, consideramos que as pesquisas empíricas sobre usos sociais dos meios de comunicação, como são amplamente realizadas nos estudos de recepção (SCHMITZ et al., 2015), por exemplo, configuram-se como situações de socialidade (MARTÍNBARBERO, 2004): momentos de pensar sobre os usos, apropriar-se dos sentidos e compartilhar impressões, sensações, críticas e preferências.

De forma geral, os entrevistados sugeriram pelo menos cinco possíveis motivações distintas para a produção de postagens sobre si mesmos: a) carência e solidão; b) desejo de criar vínculos por meio de atividades positivas; c) busca por dinheiro; d) experiência de lazer; e f) diversão e ainda tentativa de exibir-se. Cada uma dessas possibilidades apresenta mais de uma camada de sentido, o que complexifica o simples hábito de usar o Instagram. O propósito de exibir-se na internet, por exemplo, apareceu vinculado tanto a mecanismos de ostentação, quanto a processos de construção subjetiva repletos de inseguranças. Mostrar-se na rede, segundo os adolescentes, pode ser um exercício de autoconhecimento e posicionamento de si enquanto ser social. Nessa prática, 


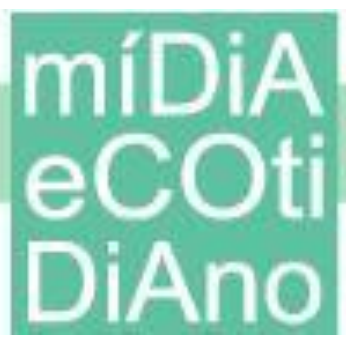

estão envolvidas dinâmicas e ajustes performáticos intimamente ligados a como cada sujeito quer ser percebido pelos outros e como se percebe também.

O tensionamento entre as noções de autenticidade e performance aparece no debate a partir de uma observação prática de uso em que pessoas aparecem no Instagram com comportamentos distintos ou daqueles que têm fora da internet, ou daqueles desempenhados na rede, mas em outro formato. Essas diferenciações foram feitas pelos entrevistados por graus de espontaneidade. Trata-se de uma maneira particular de compreensão das ações comunicativas na rede, a qual, para ser compreendida demanda uma análise atenta às pequenas impressões advindas do uso da internet e de todo o repertório individual de cada adolescente, que levam ao estabelecimento de acordos sociais. São esses pactos que constroem coletivamente referências e símbolos e consolidam parâmetros de modos de ser socialmente.

A teoria das mediações, materializada na abordagem cartográfica (MARTÍNBARBERO, 1997; 2004), nos orienta para a percepção de fenômenos culturais e comunicativos de forma mais ampla, evitando polarizações e posturas generalistas. Por isso, com base nos debates com os entrevistados, atribuímos diversos sentidos para a performance de si nas redes sociais contemporâneas, extrapolando a visão denuncista que confere a ela um status de falsidade. Isso quer dizer que os modos de performar-se citados pelos adolescentes revelam um exercício processual de localização do sujeito no mundo, de expressão de valores, de significação da existência, enfim, de dinâmicas subjetivas que articulam camadas para além da espetacularização da vida. Assim, a atividade de investigar os limites entre autenticidade e performance, nos termos de realidade e ficção, torna-se restrita diante do desafio de pensar essas noções como instâncias congêneres, que caminham em trilhos afins na tortuosa estrada de atribuição de sentido a si e ao mundo.

Percebemos que o uso cotidiano das plataformas digitais confere aos adolescentes competências de recepção (MARTÍN-BARBERO, 1997) capazes de organizar a percepção sincrônica das lógicas produtivas, por meio do estabelecimento de opiniões e juízos de valor sobre, especialmente, as atividades de outras pessoas na internet. Isto é, eles sentiram-se mais à vontade para falar sobre o que observam no acesso, do que sobre o que eles mesmos produzem. Além disso, constatamos que as percepções 


\section{míiA
eCOti
DiAno}

dos entrevistados são construídas a partir de suas próprias experiências de uso. Isso pode ser percebido nos exemplos criados e/ou rememorados nas falas, que trazem referências de uma realidade prática de uso, enunciada com a segurança de quem conhece os caminhos de acesso e acredita dominar com destreza a linguagem da web. Notamos a impaciência de muitos entrevistados para explicar, por exemplo, sobre os mecanismos de ação comunicativa usados no YouTube e no Instagram, como se fossem atividades extremamente básicas e corriqueiras - quando, em muitos casos, exigiam um domínio técnico e performático complexo.

Consideramos, por fim, que os modos de compartilhar-se indicam uma tendência contemporânea da exposição da rotina, que é apropriada pelo grupo tanto com resistência e afastamento, quanto com idealização e busca por aceitação social. Sobretudo, o que predominou foi a apresentação de uma opinião crítica sobre as práticas de acesso à internet, usando argumentos que pudessem posicionar os jovens diante de uma questão sociocultural. A maioria sempre tinha respostas e queria expressá-la com segurança, o que pode ser pensado como um sintoma de nosso tempo, no qual parece importante saber falar sobre tudo e conseguir se posicionar diante de qualquer tema. Essa última percepção em específico conduz nossa pesquisa a mais reflexões, que já estão em curso e, em breve, também serão apresentadas publicamente.

\section{Referências}

BRIGNOL, Liliane Dutra. Migrações transnacionais e usos sociais da internet: identidades e cidadania na diáspora latino-americana. 2010. Tese (doutorado em Ciências da Comunicação) Programa de Pós-graduação em Ciências da Comunicação, Universidade do Vale do Rio dos Sinos, São Leopoldo, RS, 2010.

CARRIJO, A. J. F.; SATLER, L. L. Performance na comunicação e mediações culturais. In: SATLER, L. L., et al. (Org.). Performances, mídia e cinema. Goiânia: Imprensa Universitária, 2019, p. 306-324.

CASTELLS, M. A sociedade em rede. Tradução por Roneide Venancio Majer e Klauss Brandini Gerhardt. 2. ed. São Paulo: Paz e Terra, 1999.

CERTEAU, Michel de. A invenção do cotidiano: artes de fazer. Petrópolis, Vozes, 1994.

COIMBRA, C., et al. Subvertendo o conceito de adolescência. Arquivos Brasileiros de Psicologia, v. 57, n. 1, p. 2-11, 2005. 
DUARTE, J. Entrevista em profundidade. In: DUARTE, J.; BARROS, A. (Org.). Métodos e técnicas de pesquisa em comunicação. 2. ed. São Paulo: Atlas, 2010, p. 62-83.

GASKELL, G. Entrevistas individuais e grupais. In: BAUER, M. W.; GASKELL, G. Pesquisa qualitativa com texto, imagem e som. 2. ed. Petrópolis, RJ: Editora Vozes, 2003, p. 64-89.

GIDDENS, A. Modernidade e identidade. Tradução de Plínio Dentzien. Rio de Janeiro: Zahar, 2002.

GEERTZ, C. A interpretação das culturas. LTC: Rio de Janeiro, 1989.

GOFFMAN, E. A representação do eu na vida cotidiana. Tradução de Maria Célia Santos Raposo. 20 ed. Petrópolis, RJ: Vozes, 2018.

GÓMEZ, G. O. O telespectador frente à televisão: uma exploração do processo de recepção televisiva. Communicare, São Paulo, v. 5, n. 1, p. 27-42, 2005.

HORTA, N. C.; SENA, R. R. Abordagem ao adolescente e ao jovem nas políticas públicas de saúde no Brasil: um estudo de revisão. Physis, Rio de Janeiro, v. 20, n. 2, p. 475-495, 2010.

JENKINS, H. Cultura da Convergência. 2. ed. São Paulo: Aleph, 2009.

LEMOS, A. A crítica da crítica essencialista da cibercultura. Matrizes. São Paulo, v. 9, n. 1, p. 29-51, 2015.

MACHADO, M. A teoria da antropologia digital para as humanidades digitais. Z Cultural. Rio de Janeiro, ano XII, n. 2, n.p., 2017.

MARTÍN-BARBERO, J. Dos meios às mediações: comunicação, cultura e hegemonia. Tradução por Ronald Polito e Sérgio Alcides. 1. ed. Rio de Janeiro: UFRJ, 1997.

Ofício de cartógrafo: travessias latino-americanas da comunicação na cultura. Tradução por Fidelina González e Renata Pallotini. São Paulo: Loyola, 2004.

MATTOS, C. L. G. A abordagem etnográfica na investigação científica. In: MATTOS, C. L. G., CASTRO, P. A., (Orgs.). Etnografia e educação: conceitos e usos. Campina Grande: EDUEPB, 2011, p. 49-83.

RAGO, M. A aventura de contar-se. Campinas, SP: Unicamp, 2013.

RIESMAN, D. A multidão solitária. São Paulo, Perspectiva, 1995.

SANTAELLA, L. Sujeito, subjetividade e identidade no ciberespaço. In: LEÃO, L. (Org.). Derivas: cartografias do ciberespaço, São Paulo: Annablume; Senac, 2004.

SCHECHNER, R. Performance Studies: an introduction. Nova Iorque: Routledge, 2002.

SCHMITZ, D.; et al. Estudos de recepção: estado da questão e os desafios pela frente.

Intercom. São Paulo, v. 38, p. 109-128, 2015.

SIBILIA, P. Autenticidade e performance: a construção de si como personagem visível. Fronteiras, Porto Alegre, v. 17, n. 3, p. 353-364, 2015. 
SILVEIRA, F. Experiências etnográficas no campo da Comunicação. Unirevista, v.1, n. 1, p. 23-31, 2016.

SILVERSTONE, R. Complicity and collusion in the mediation of everyday life. New Literary History, v. 33, n. 4. p. 761-780, 2002.

THOMPSON, J. A interação mediada na era digital. Matrizes, São Paulo, v. 12, n. 3, p. 17-44, 2018. 